\title{
Crohn's disease: natural history and treatment
}

\author{
J. E. LENNARD-JoNES \\ University College and St Mark's Hospitals, London
}

AN EXTENSIVE literature is now available on the pathological anatomy and its variations in Crohn's disease. These studies, correlated with clinical observation, have built up a picture of a disease with several characteristics, only some of which may be present in each case and none of which are invariably present in this disease and no other. Further advance must await information about the aetiology and deranged mechanisms underlying the disorder. For the moment, Crohn's disease is best regarded as a clinicopathological syndrome without defining features, the diagnosis being made on the presence of some or all of the characteristic features associated with it.

Taxonomic studies must always precede investigation of dynamic changes in a species or a disease. Enough is now known about the recognition of Crohn's disease without operation for more information to be accumulated on its behaviour and development. Where and in whom does the disease occur? What is the earliest detectable lesion, how do the lesions change with time, is progression inevitable and is this a continuous process, or can regression occur? How can the development of the disease be altered by environmental factors, drugs or surgery? About many of these questions, our knowledge is very limited, largely because up to now the diagnosis has been made only when gross structural changes are present in the gut and excision of the diseased bowel has been indicated. There are, therefore, more data on the behaviour of the disease after surgical treatment than on the early phases of the disorder. With improved radiological techniques and increased awareness of the condition, the diagnosis is now often being made at a stage before surgical treatment is clearly indicated and knowledge should become available on its behaviour with and without drug treatment.

Where do the changes of Crohn's disease occur in the gut?

In their original description Crohn, Ginzburg
\& Oppenheimer (1932) termed the disorder 'regional ileitis' because in all their cases the. structural changes were limited to the terminal $\vec{\omega}$ ileum. It soon became apparent that the disease ${ }^{\circ}$ can affect any portion of the gut, though recog-8 nition that it can affect the colon, rectum or 3 anus, without small bowel disease, has been $\overrightarrow{+}$ generally accepted only during the last few years o (Lockhart-Mummery \& Morson, 1964 ; Janowitz, $\vec{G}$ Lindner \& Marshak, 1965; Gray, LockhartMummery \& Morson, 1965). The frequency of $\perp$ the disease in different parts of the gut is difficult? to assess because many cases of colonic Crohntsdisease are diagnosed as idiopathic proctocolitis $\mathscr{D}$ and because reports from special centres tend represent selected series. The following figuregs 3 show the distribution of the disease in the gut over a 10-year period at the Central Middlesex Hospital, London ; the figures for Crohn's disease confined to the colon are probably undexestimated as the criteria for making this diagnosis were not described until the later years of the period.

\section{TABLE 1}

Distribution of the lesion in 101 cases seen at the Central Middlesex Hospital, 1954-63

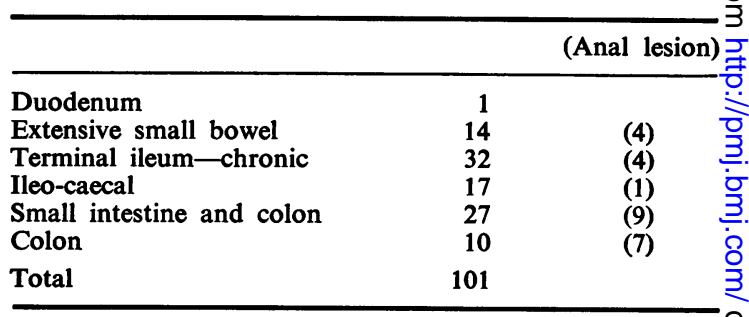

Figures in parentheses show the number of patients who had an associated anal lesion.

It will be seen that the terminal ileum was involved in seventy-six of the 101 patients support-or ing the impression that this region of the gut $N$ is particularly liable to be affected.

In whom does the disease occur?

Evans \& Acheson (1965) in their survey 
the Oxford area found a prevalence of nine per 100,000 for regional enteritis in the whole population. It seems likely that this figure is an underestimate because of the difficulty in diagnosing the disease in other parts of the small intestine or colon. For example, the ten cases described as 'mixed forms' in their series, and classified with colitis, would probably now be described as Crohn's disease of the colon.

There is a definite familial tendency in Crohn's disease and Hinton (personal communication 1967) found that 145 patients with Crohn's disease had nine affected relatives among 625 relatives at risk. Other data suggests that ankylosing spondylitis (McBride et al., 1963) and, perhaps, iritis also tend to run in the same families, not necessarily in association with intestinal disease. There is also evidence that Crohn's disease occurs more frequently among those of the Jewish religion than among other races (Acheson, 1960).

\section{What is the earliest detectable lesion?}

The relationship of Crohn's disease to acute ileitis, usually diagnosed at operation for supposed appendicitis, is not entirely clear and much depends on the definition of acute ileitis. Followup studies suggest that the lesions of acute ileitis, with a history 1 week or less, do not become chronic (Atwell, Duthie \& Goligher, 1965). It seems likely that at least some of these cases are due to a specific infection.

In surgical specimens removed for chronic regional ileitis minute lesions may be found involving the otherwise normal ileum proximal to the diseased area. These lesions are ulcerated lymphoid follicles and Morson (1965) believes that the earliest lesion of Crohn's disease may be hyperplasia of a lymphoid follicle followed by suppuration and ulceration. A similar lesion may occasionally be found in a rectal biopsy specimen when obvious disease affects the bowel proximally.

\section{How do the lesions change with time?}

It is important to know whether the lesions are always progressive, and, if so, whether this is a continuous or intermittent process. From the point of view of medical management, knowledge is needed as to the potential reversibility of the lesions and their capacity to heal, though perhaps with irreversible changes. The likelihood that lesions will spread along the length of the gut may determine the advisability of surgical treatment ; there have also been suggestions that surgical treatment may increase the likelihood of such spread. Finally, it would be interesting to know whether 'skip lesions' arise as new events in the illness or whether the time of onset of all lesions is the same though the rate of development may differ.

There is almost no data with which to attempt an answer to these questions. Study of individual cases suggests that the early lesions are reversible, sometimes spontaneously, and that the lesions tend to remain localized (without surgical treatment) to areas originally involved. Over periods of time, however, recurrent exacerbations of inflammation lead to progressively more severe damage to the diseased segments. The following case report illustrates these features:

Mrs C.A. At the age of 40 this patient presented with a history of rectal bleeding and a tendency to constipation during the previous 11 years. Sigmoidoscopy revealed an inflamed rectal mucosa; barium enema was normal.

Symptoms persisted intermittently for 7 years when a sharp relapse occurred with diarrhoea, fever, weight loss and anaemia. A barium enema (Fig. 1) showed severe colonic disease. The symptoms settled with bed rest and blood transfusion.

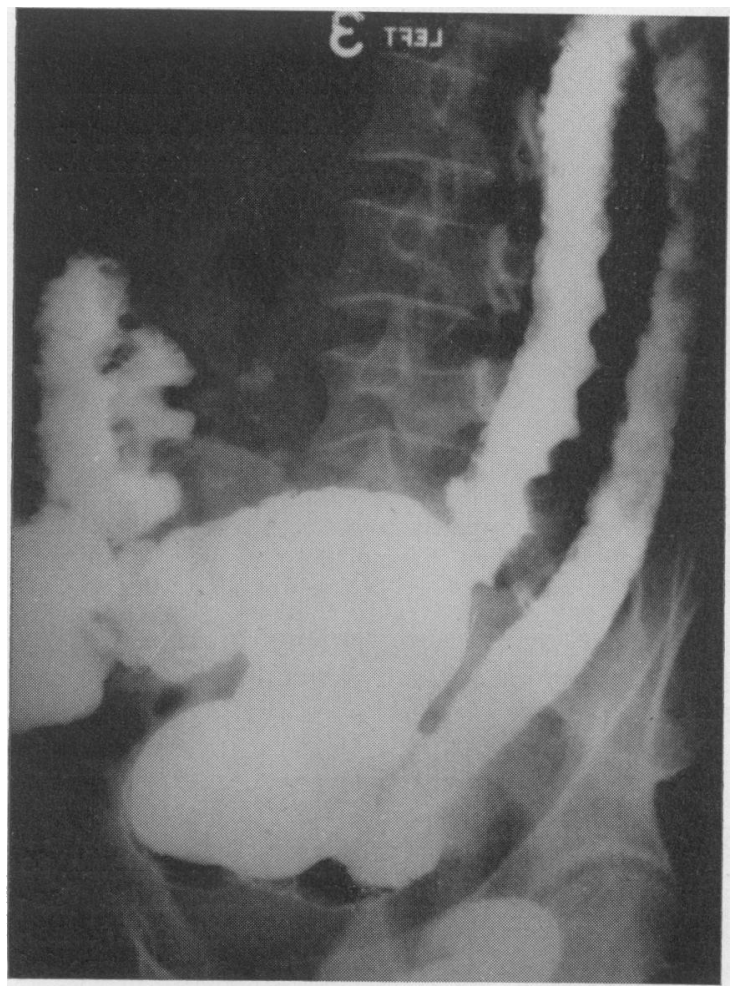

Fig. 1. Case C.A. Barium enema at the age of 47 showing severe disease with ulceration of the transverse, descending and sigmoid colon. 


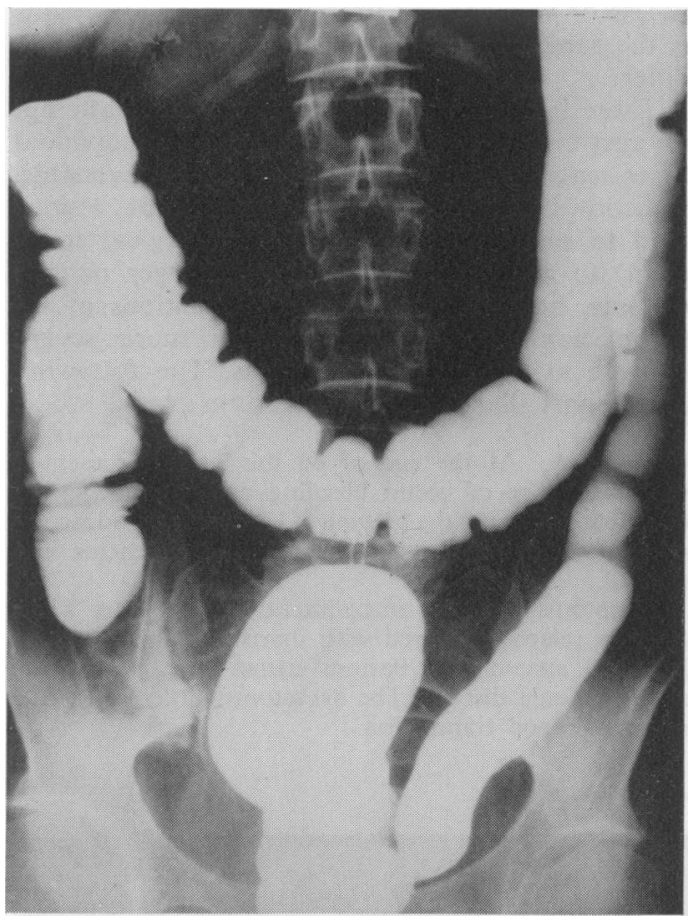

Fig. 2. Case C.A. Barium enema at the age of 53 when symptoms were slight showing return to normal.

Mild intermittent symptoms persisted for 6 years when another barium enema (Fig. 2) showed no abnormality.

Seven years later, at the age of 64 , a severe relapse occurred with diarrhoea and abdominal pain. Barium enema (Fig. 3) showed marked changes in the transverse and descending colon. Proctocolectomy was performed. The patient was well when last seen 4 years later.

Study of many more patients over periods of years is needed before generalizations can be made.

\section{The effect of medical treatment}

\section{(a) General measures}

Some patients with Crohn's disease seem to improve with rest. The effectiveness of a prolonged sanatorium regime has never been formally assessed in such patients. One instance of spontaneous improvement in the disease has already been commented upon, and the possibility of such improvement must always be con-

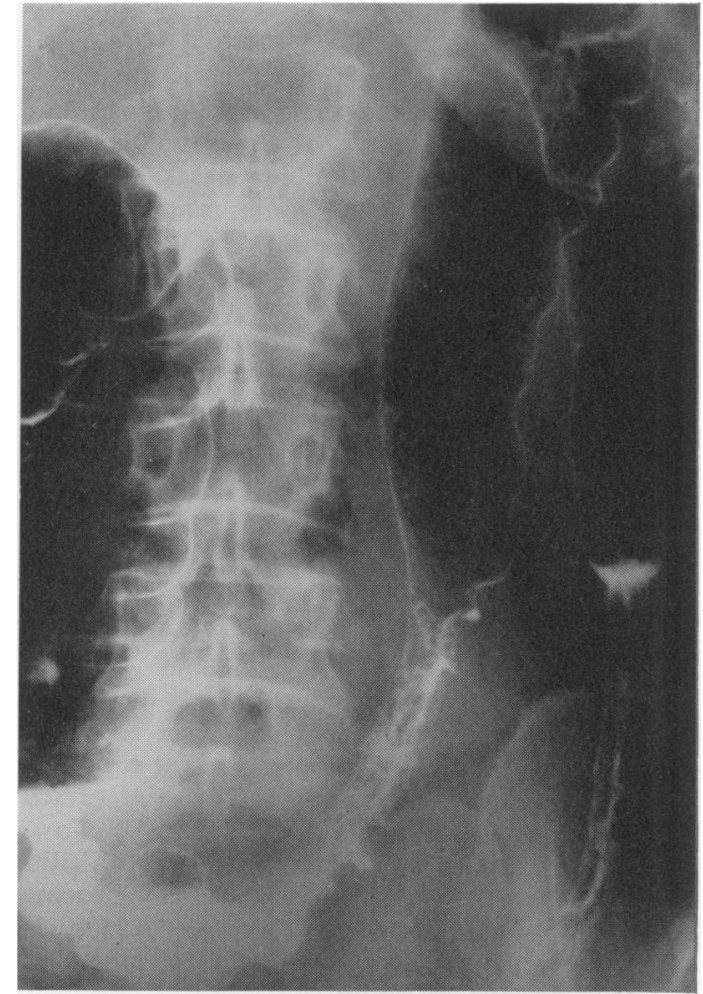

Fig. 3. Case C.A. Double-contrast barium enema at the age of 60 showing segmental lesions of the transverse and descending colon with less severe disease of the splenic flexure.

sidered when assessing any form of treatment. Some patients are also seen with gross X-ray changes of disease but who are completely, or almost, symptom-free and who are in excellent health. Such patients require no treatment.

The emphasis as regards diet should be on nutritious meals, rich in protein. A stenotic lesion of the intestine is a good indication for a low residue diet to reduce bolus colic. Dietary restriction is not otherwise indicated except after extensive resection of small intestine when a lowfat, high-protein, high-carbohydrate diet is beneficial.

Mineral and vitamin supplements may be required. Any patient who has had more than $3 \mathrm{ft}$ of distal ileum resected should receive regular injections of vitamin $B_{12}$ (Schofield, 1965).

(b) Sulphonamides and antibiotics

Poorly absorbed sulphonamides, such as phthalylsulphathiazole, sometimes appear helpful. Sulphasalazine is worth trying but its effectiveness 
is difficult to assess. My own practice is often to try these drugs before using corticosteroids. Some physicians give a broad-spectrum antibiotic over long periods with or without corticosteroid treatment. Anti-tuberculous drugs are not helpful in our experience.

\section{(c) Corticosteroids and corticotrophin}

Three analyses of treatment with corticosteroid drugs or corticotrophin have shown that their use is often followed by symptomatic and objective improvement in the patient's condition (Jones \& Lennard-Jones, 1966 ; Jones, LennardJones \& Lockhart-Mummery, 1966 ; Sparberg \& Kirsner, 1966). In some patients apparent radiological healing of colonic ulceration has been observed during treatment but very often the $\mathrm{X}$-ray appearances show little change despite good clinical improvement. Although the early results may be encouraging, the late results are often disappointing. Where improvement does occur, long-continued treatment is often necessary to maintain it ; the minimal dose needed can be established only by making regular attempts to reduce the dose and withdraw the treatment, maintaining the dose at a slightly greater level than that at which evidence of disease activity recurs. Long-continued treatment is justifiable and often of great benefit in the two groups of patients for whom surgery is inadvisable, those with extensive small-bowel disease and those who have had more than one small-bowel resection. The place of long-continued steroids in the management of localized disease in the small intestine or of colonic disease, both of which can be treated surgically, is more doubtful. Corticosteroids are best avoided where the disease is complicated by stricture, internal fistula or abscess formation. The most favourable indications for corticosteroid treatment are a patient with a short history, marked systemic reaction to the disease, in the form of fever and perhaps eye, skin or joint complications, and extensive mucosal involvement of the intestine.

Topical corticosteroid therapy using a retention enema containing $20 \mathrm{mg}$ of prednisolone 21-phosphate in $100 \mathrm{ml}$ of water, or suppositories each containing $5 \mathrm{mg}$ of prednisolone 21-phosphate, is often beneficial in rectal and distal colonic disease.

\section{(d) Anti-metabolites}

Azathioprine and related drugs may have a place in the management of Crohn's disease but their usefulness is not so far established or defined. This treatment should only be used as a trial in exceptional circumstances and under close supervision with blood counts twice weekly to begin with.

\section{The effect of surgical treatment}

Surgical treatment may take the form of a diversion procedure, usually with exclusion of the diseased segment, or of a resection of the diseased bowel. An ileo-transverse colostomy with exclusion of the diseased terminal ileum was originally recommended as treatment for regional ileitis because the mortality from this operation was less than from resection (Crohn \& Yarnis, 1958). With improved techniques this difference is no longer a factor and most British surgeons prefer to perform resection. Interest in a diversion ileostomy for colonic Crohn's disease has been stimulated by two reports that the inflammation settles once this has been done (Truelove, Ellis \& Webster, 1965 ; Kivel, Taylor \& Oberhelman, 1967). Experiments in which ileostomy effluent is infused through the colon suggest that the disease may be activated by passage of intestinal contents. These results are most interesting but so far the ultimate test of this treatment, to restore intestinal continuity, has been performed in few patients and the follow-up is short. Experience of diversion operations for colonic Crohn's disease at St Mark's Hospital has not been favourable (Jones et al., 1966) but results may depend on selection of suitable patients.

A major problem after surgical resection is the liability to recurrence of the disease, usually at the anastomosis. The relapse rate in patients with disease of the terminal ileum treated by resection at the Central Middlesex and St Mark's Hospitals has been calculated by the actuarial method (Lennard-Jones \& Stalder, 1967). The estimated symptomatic relapse rate at 5 years was about one-third, and at 10 years a little over half of the patients. The estimated need for a further resection was about one-sixth at 5 years and one-quarter at 10 years. This estimate of the need for further resection within five years is very similar to the figure of $18 \%$ recently reported from Manchester (Schofield, 1965). Recurrences also occur after limited resections for colonic Crohn's disease though their frequency is difficult to assess. The incidence of recurrent disease in the ileum after excision of colonic Crohn's disease with formation of an ileostomy has been low at St Mark's Hospital (Jones et al., 1966).

\section{Conclusion}

Our knowledge of the mode of development of Crohn's disease and of factors which influence its course is very limited. No specific medical or surgical treatment is at present known and 
the patient often requires both medical and surgical management at different stages of the illness. Medical treatment is particularly important in extensive disease of the small bowel and these patients are often greatly helped by longterm corticosteroid therapy. In localized disease of the small bowel, surgical measures are often needed to establish the diagnosis, to remove ulcerated or stenosed bowel, or for dealing with fistula formation. In Crohn's disease affecting the large bowel, medical treatment with sulphonamides or corticosteroids often relieves the acute symptoms but surgical treatment is frequently necessary later. At present limited resections for localized colonic disease and total colectomy for diffuse disease appear to give good results. Certain patients may benefit from a diversion operation but the indications for this procedure are not yet clearly established.

\section{References}

ACHeson, E.D. (1960) The distribution of ulcerative colitis and regional enteritis in United States veterans with particular reference to the Jewish religion. Gut, 1, 291.

Atwell, J.D., Duthie, H.L. \& Goligher, J.C. (1965) The outcome of Crohn's disease. Brit. J. Surg. 52, 966.

Crohn, B.B., Ginzburg, L. \& Oppenheimer, G.D. (1932) Regional ileitis: a pathologic and clinical entity. J. Amer. med. Ass. 99, 1323.

CroHn, B.B. \& YARNIS, H. (1958) Regional Ileitis, 2nd edn. Grune \& Stratton, New York.
Evans, J.G. \& ACheson, E.D. (1965) An epidemiological study of ulcerative colitis and regional enteritis in the Oxford area. Gut, 6, 311.

Gray, B.K., Lockhart-Mummery, H.E. \& MORSON, B.C. (1965) Crohn's disease of the anal region. Gut, 6, 515.

JANOWITZ, H.D., LiNDNER, A.E. \& MARSHAK, R.H. (1965) Granulomatous colitis: Crohn's disease of the colon. J. Amer. med. Ass. 191, 825.

JONES, J.H. \& LENNARD-Jones, J.E. (1966) Corticosteroids and corticotrophin in the treatment of Crohn's disease. Gut, 7, 181.

Jones, J.H., LenNaRd-Jones, J.E. \& Lockhart-Mummery, H.E. (1966) Experience in the treatment of Crohn's disease of the large intestine. Gut, 7, 448.

Kivel, R.M., TAYloR, K.B. \& Oberhelman, H. (1967) Response to bypass ileostomy in ulcerative colitis and Crohn's disease of the colon. Lancet, ii, 632.

Lennard-Jones, J.E. \& Stalder, G.A. (1967) Prognosis after resection of chronic regional ileitis. Gut, 8, 332.

LOCKhart-Mummery, H.E. \& Morson, B.C. (1964) Crohn's disease of the large intestine. Gut, 5, 493.

McBride, J.A., King, M.J., Baikie, A.G., Crean, G.P. \& Sircus, W. (1963) Ankylosing spondylitis and chronic inflammatory diseases of the intestines. Brit. med. $J$. ii, 483.

Morson, B.C. (1965) Crohn's disease of the small intestine. The Small Intestine (Ed. by A.C. Thackray and F. Avery Jones). Blackwell Scientific Publications, Oxford.

SCHOFIELD, P.F. (1965) The natural history and treatment of Crohn's disease. Ann. roy. Coll. Surg. Engl. 36, 258.

SPARBERG, M. \& KIRSNER, J.B. (1966) Long-term corti costeroid therapy for regional enteritis: an analysis oP 58 courses in 54 patients. Amer. J. dig. Dis. 11, 865 .

Truelove, S.C., Ellis, H. \& Webster, T.U. (1965) Plac庐 of a double-barrelled ileostomy in ulcerative colitis an\& Crohn's disease of the colon: a preliminary report. Bri尺 med. J. i, 150. 